\title{
The form of the conditioned hypoalgesic response resulting from preexposure to a heat stressor depends on the pain test used
}

\author{
H. FOO and R. F. WESTBROOK \\ University of New South Wales, Sydney, Australia
}

\begin{abstract}
Preexposure to the heated floor of a hot-plate apparatus resulted in conditioned hypoalgesic responses among rats tested in that apparatus. These responses were unaffected by naloxone or a history of morphine among rats tested on the heated floor, but were reversed by naloxone or a history of morphine in rats tested with formalin on the nonheated floor of the apparatus. The results were taken to mean that apparatus cues paired with the heated floor conditionally activated multiple mechanisms of pain control; the nonopioid mechanisms were engaged by the pain that was provoked by the test exposure to the heated floor and the opioid mechanisms were recruited by the pain that was produced by formalin.
\end{abstract}

Endogenous mechanisms of pain control can be activated by Pavlovian conditioned stimuli (CSs) that have become dangerous as a result of signaling an aversive unconditioned stimulus (US). However, the conditions that determine which mechanism of pain control is selected by an aversively conditioned CS remain controversial (see Fanselow, 1991; Maier, 1989, for reviews). In particular, there have been inconsistent reports concerning the neurochemistry underlying conditionally controlled decreases in pain sensitivity/reactivity. On the one hand, there is evidence for an involvement of critical opioid synapses at one or more locations in an endogenous pain inhibitory pathway, because conditionally controlled hypoalgesic responses have been reversed by an opioid antagonist and/or have been cross-tolerant with an opioid agonist (Fanselow \& Baackes, 1982; Fanselow \& Helmstetter, 1988; Grau, 1987; Lichtman \& Fanselow, 1991; Maier, 1989; Watkins, Cobelli, \& Mayer, 1982; Williams, Worland, $\&$ Smith, 1990). On the other hand, several investigators (Chance \& Rosecrans, 1979a, 1979b; Greeley \& Westbrook, 1990; Lichtman \& Fanselow, 1991; Ross \& Randich, 1985; Westbrook, Greeley, Nabke, Swinbourne, \& Harvey, 1991) have reported a failure to reverse conditionally controlled hypoalgesic responses by naloxone or naltrexone and/or have shown that such responses are not cross-tolerant with morphine.

Several factors may have contributed to these inconsistent findings. One of these is variations across experiments in the level of aversiveness when pain sensitivity/reactivity

\footnotetext{
This research was supported by a grant from the Australian Research Council and was approved by the Committee for the Ethical Use of Animals in Research and Teaching at the University of New South Wales. The authors are grateful to A. J. Good, J. A. Harris, and M. J. Kiernan for assistance. Address correspondence to R. F. Westbrook, School of Psychology, University of New South Wales, P.O. Box 1, Kensington 2033, Sydney, Australia.
}

has been assessed. There is evidence that indicates that the degree to which the CS arouses an aversive or defensive motivational system determines the neurochemistry of the resulting hypoalgesic response in such a way that opioid mechanisms are replaced by nonopioid ones as the CS becomes more aversive or frightening (Lichtman \& Fanselow, 1991). However, in the present experiments, we examined the role of a second factor-the nature of the test used to assess conditional changes in pain sensitivity/reactivity. Evidence for an opioid mediation of hypoalgesic responses has been typically obtained when rats have been exposed to an aversively conditioned CS and tested for either latencies to tail flick (Grau, 1987; Lichtman \& Fanselow, 1991; Maier, 1989; Watkins et al., 1982) or for frequency/duration of responses (licks/lifts) to the pain produced by an injection of formalin into the paw (Fanselow \& Baackes, 1982; Fanselow \& Helmstetter, 1988; Williams et al., 1990). Evidence for conditional activation of nonopioid mechanisms has been reported when rats have been tested for latencies either to remove their tails from a localized source of heat (Chance \& Rosecrans, 1979a, 1979b; Lichtman \& Fanselow, 1991) or to paw lick in response to a heated floor (Greeley \& Westbrook, 1990; Ross \& Randich, 1985; Westbrook, Greeley, Nabke, Swinbourne, \& Harvey, 1991). Thus, both opioid and nonopioid mechanisms can mediate conditionally activated hypoalgesic responses in the tail-flick procedure. However, opioid, rather than nonopioid mechanisms appear to be engaged in the formalin test (but see Fanselow, 1984), whereas nonopioid, rather than opioid mechanisms seem to be recruited in the hot-plate paradigm.

In the present experiments, we examined the role of the pain test in determining the form of conditioned hypoalgesic responses by exposing rats to the heated floor of a hot-plate apparatus and testing them in that apparatus with acute or chronic pain. The acute pain test consisted of reexposing the rats to the heated floor and measuring 
their paw-lick latencies; the chronic pain test involved reexposing the rats to the nonheated floor of that apparatus and measuring the incidence of licks/lifts of a formalininjected paw. Previous findings (Greeley \& Westbrook, 1990; Westbrook, Greeley, Nabke, Swinbourne, \& Harvey, 1991) have shown that preexposure to the heated floor would result in conditioned hypoalgesic responses unaffected by naloxone or a history of morphine among the rats tested on the heated floor. Therefore, the question of major interest addressed by the present experiments concerns the neurochemistry underlying the conditioned hypoalgesic responses among rats with formalin pain preexposed to the heated floor and tested on the nonheated floor of that apparatus.

\section{EXPERIMENTS 1A AND 1B}

The experiments involved four groups that differed according to whether they were exposed to a heated (Groups Hot) or nonheated (Groups Amb) floor of a hot-plate apparatus, and reexposed (Groups Ext) or not reexposed (Groups Home) to the nonheated floor of the apparatus prior to the pain test. The first aim was to confirm that the rats exposed to the heated floor and not reexposed to the apparatus (Group Hot/Home) would show a decrease in sensitivity/reactivity on the subsequent pain test compared with those that had not previously been subjected to pain in that apparatus (Groups Amb/Home and Amb/ Ext). The second aim of these experiments was to demonstrate that the decrease in pain sensitivity/reactivity expected among the rats in Group Hot/Home would be reduced by an extinction procedure that exposed conditioned rats to the nonheated floor of the hot-plate apparatus (Group Hot/Ext) before the pain test. The test consisted of either exposing rats to the heated floor and measuring latencies to paw lick (Experiment $1 \mathrm{~A}$ ) or placing rats on the nonheated floor of the apparatus and recording the incidence of licks/lifts of a formalin-injected paw (Experiment 1B). The experiments were conducted separately, but are presented together for convenience of exposition.

\section{Method}

Subjects. In each experiment, there were 20 experimentally naive, male Wistar rats weighing between 250 and $340 \mathrm{~g}$. The rats in all of the experiments were obtained from the colony of SpecificPathogen-Free rats maintained by the University of New South Wales and were housed in plastic boxes $(65 \times 40 \times 22 \mathrm{~cm})$ during the course of the experiments. There were 5 rats to a box, with food and water continuously available. The boxes were kept in a colony room under natural lighting. The experiments were conducted between 900 and $1400 \mathrm{~h}$.

Apparatus. The hot-plate apparatus consisted of a Plexiglas chamber ( $24 \mathrm{~cm}$ wide $\times 48 \mathrm{~cm}$ high) with a copper floor ( $1 \mathrm{~mm}$ thick) that was fixed $12 \mathrm{~cm}$ above the base of the chamber. The portion of the chamber below the copper floor was perforated with $3-\mathrm{cm}$ diam holes to permit the circulation of water under the floor. The chamber stood in a water bath whose temperature could be maintained at a particular value $\left( \pm 0.5^{\circ} \mathrm{C}\right)$ by a Haake D1 Open Bath Circulator. The laboratory also contained wooden boxes $(30 \mathrm{~cm}$ long $\times 27 \mathrm{~cm}$ wide $\times 30 \mathrm{~cm}$ high) with transparent Plexiglas doors.
These served as chambers where the rats were kept in isolation when brought to the laboratory from the adjacent colony room. The floor of the hot-plate apparatus was cleaned with $0.5 \%$ acetic acid solution after exposure of each rat (Fanselow \& Helmstetter, 1988).

Procedure. The rats were handled across 3 successive days and then assigned to weight-matched groups $(n=5)$ in each experiment. On Day 1 , they were placed into the wooden chambers for $30 \mathrm{~min}$ and exposed to the hot-plate apparatus for $60 \mathrm{sec}$. The water temperature surrounding the floor was maintained at $52^{\circ} \mathrm{C}$ for the rats in Groups Hot/Home and Hot/Ext and at $23^{\circ} \mathrm{C}$ for those in Groups Amb/Home and Amb/Ext. On Days 2, 3, and 4, the rats in Groups Hot/Ext and Amb/Ext were placed into the wooden chambers for $30 \mathrm{~min}$ and exposed to the $23^{\circ} \mathrm{C}$ floor of the hot-plate apparatus for $10 \mathrm{~min}$. On these days, the rats in Groups Hot/Home and Amb/Home were handled in the colony room. On Day 5, they were tested. In Experiment $1 \mathrm{~A}$, the rats were exposed for $30 \mathrm{~min}$ to the wooden chambers and placed for a maximum of $60 \mathrm{sec}$ onto the $52^{\circ} \mathrm{C}$ floor of the hot-plate apparatus. The latencies to paw lick (front or back) were recorded by using push buttons connected to a microprocessor. In Experiment 1B, the rats were anesthetized with $5 \%$ halothane (Fluothane, ICI Pharmaceuticals) delivered in $750 \mathrm{mmHg}$ of nitrous oxide and $300 \mathrm{mmHg}$ of oxygen. This was done to permit precise injection of formalin, and at the request of the ethics committee of the University of New South Wales. While still unconscious, the rats were injected with $0.05 \mathrm{ml}$ of a $3 \%$ formalin solution (diluted with distilled water) into the dorsal surface of the right front paw (Dubuisson \& Dennis, 1977). After recovery from the anesthetic (approximately $12 \mathrm{~min}$ ), they were exposed to the wooden chambers for $30 \mathrm{~min}$ and placed onto the $23^{\circ} \mathrm{C}$ floor of the hot-plate apparatus for $5 \mathrm{~min}$. The rats were observed every $2 \mathrm{sec}$ on the $23^{\circ} \mathrm{C}$ floor of the hot-plate apparatus, and push buttons connected to a microprocessor were used to record the occurrence of responses (licks or lifts) directed at the formalin-injected paw.

Statistical analysis. To determine the significance of any betweengroup differences in each of the experiments, sets of post hoc, orthogonal contrasts were written and the decision-wise error rate was controlled at the .05 level with the technique described by Rodger (1967).

\section{Results and Discussion}

In Experiment 1A, there were no significant differences $(F<1.0)$ between paw-lick latencies on the initial exposure to the heated floor among the rats in Groups Hot/ Home $(M=11.5, S E M=2.4)$ and Hot $/ \operatorname{Ext}(M=14.8$, $S E M=2.6$ ). The mean latencies with which the rats in each of the four groups paw licked on test are shown in the left side of Figure 1. The rats in Group Hot/Home paw licked with significantly longer latencies than did those in the other three groups $[F=27.3 ; F \mathrm{c}(3,16)=6.3]$, confirming that exposure to a heated floor results in hypoalgesic responses when rats are reexposed to that floor. These hypoalgesic responses were reduced by interpolated exposures to the nonheated floor in the period between the initial and test exposures to the heated floor, because the rats in Group Hot/Ext did not differ in their paw-lick latencies from those in Groups Amb/Home and Amb/Ext $(F<1.0)$. This reduction in paw-lick latencies was not a general consequence of repeated exposures to the nonheated floor, but was specific to the rats in Group Hot/Ext that had received those exposures between the initial and test exposures to the heated floor. Evidence for this assertion comes from the failure to detect any significant differences between paw-lick latencies $(F<1.0)$ among the rats given single (Group Amb/Home) versus multi- 


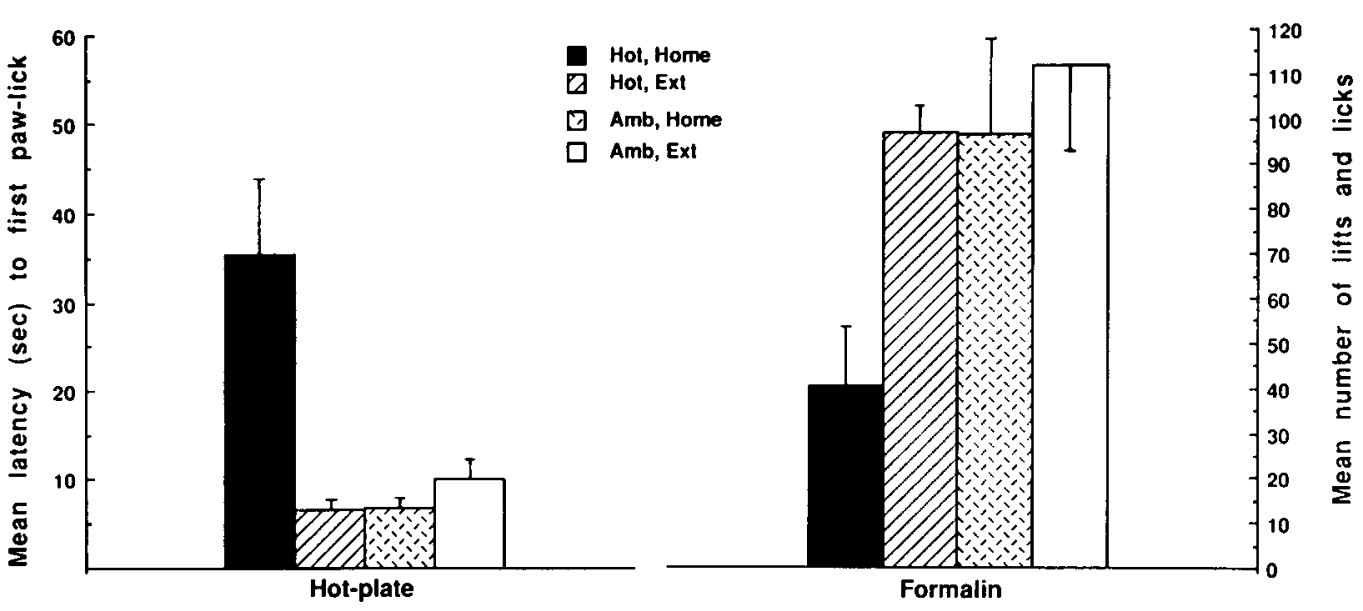

Figure 1. Mean (+1 SEM) latencies to paw lick in Experiment 1A (left) and mean $( \pm 1 S E M)$ number of paw licks and paw lifts in Experiment $1 B$ (right). Rats were preexposed to the heated (Hot) or nonheated (Amb) floor and exposed (Ext) or not exposed (Home) to the nonheated floor before test.

ple (Group Amb/Ext) exposures to the nonheated floor in advance of the pain test.

In Experiment 1B, there were no significant differences $(F<1.0)$ between paw-lick latencies on the initial exposure to the heated floor among the rats in Groups Hot/ Home $(M=8.1, S E M=1.4)$ and Hot/Ext $(M=8.9$, $S E M=2.5)$. The mean number of pain responses to the formalin-injected paw when the rats in each of the groups were tested on the nonheated floor of the hot-plate apparatus are shown in the right side of Figure 1. The rats in Group Hot/Home displayed significantly less pain responses than did those in the other three groups $(F=13.8)$, showing that exposure to the heated floor resulted in hypoalgesic responses on the formalin test. The hypoalgesic responses observed among the rats in Group Hot/Home were not mediated by nonassociative processes resulting from preexposure to the heated floor, because there were no significant differences between pain responding among the rats in Group Hot/Ext and those in Groups Amb/Home and Amb/Ext $(F<1.0)$. The reduction in hypoalgesic responses among the rats in Group Hot/Ext was a result of extinction rather than of familiarity with the nonheated floor, because there were no significant differences $(F<$ $1.0)$ between pain responding among the rats given single (Group Amb/Home) versus multiple (Group Amb/Ext) exposures to the nonheated floor.

\section{EXPERIMENTS 2A AND 2B}

The results of Experiments 1A and 1B support the view that the association between apparatus cues and some representation of the pain produced by exposure to a heated floor results in the activation of antipain mechanisms when rats are tested in the presence of those cues with either acute or chronic pain. In Experiments $2 \mathrm{~A}$ and $2 \mathrm{~B}$, rats were tested under the influence of either naloxone or saline in an initial investigation of the nature of the antipain mechanisms activated by reexposure to the apparatus cues paired with the heated floor. In both experiments, four groups of rats received exposure to either a heated or nonheated floor and a test under either naloxone or saline. The rats were tested for latencies to paw lick in response to a heated floor in Experiment 2A, and for the incidence of responding to a formalin-injected paw on a nonheated floor in Experiment 2B.

\section{Method}

Subjects and Apparatus. In each experiment, there were 40 experimentally naive, male Wistar rats weighing between 234 and $450 \mathrm{~g}$. The apparatus was that used for Experiments $1 \mathrm{~A}$ and $1 \mathrm{~B}$.

Drugs. Naloxone hydrochloride (Sigma) was dissolved in 0.9\% w/v saline solution and injected at a dose of $2.5 \mathrm{mg} / \mathrm{kg}$. Naloxone and physiological saline were injected subcutaneously into the dorsal area of the neck in a volume of $1.0 \mathrm{ml} / \mathrm{kg}$.

Procedure. After handling, the rats were allocated to weightmatched groups $(n=10)$ in each experiment. On Day 1, they were injected with saline, placed into the wooden chambers for $30 \mathrm{~min}$, and exposed for $60 \mathrm{sec}$ to either the $52^{\circ} \mathrm{C}$ floor of the hot-plate apparatus (Groups Hot/Sal and Hot/Nal), or to the $23^{\circ} \mathrm{C}$ floor of that apparatus (Groups Amb/Sal and Amb/Nal). On Day 2, the rats were tested. In Experiment $2 \mathrm{~A}$, the rats were injected with saline (Groups Hot/Sal and Amb/Sal) or with naloxone (Groups Hot/Nal and $\mathrm{Amb} / \mathrm{Nal}$ ), placed into the wooden chambers for $30 \mathrm{~min}$, and tested for a maximum of $60 \mathrm{sec}$ on the $52^{\circ} \mathrm{C}$ floor of the hot-plate apparatus. In Experiment 2B, rats were injected with formalin in the manner described previously. After recovery from the anesthetic, they were injected either with saline (Groups $\mathrm{Hot} / \mathrm{Sal}$ and $\mathrm{Amb} / \mathrm{Sal}$ ) or naloxone (Groups $\mathrm{Hot} / \mathrm{Nal}$ and $\mathrm{Amb} / \mathrm{Nal}$ ), placed into the wooden chambers for $30 \mathrm{~min}$, and tested for $5 \mathrm{~min}$ on the $23^{\circ} \mathrm{C}$ floor of the hot-plate apparatus. Paw-lick latencies (Experiment 2A) and incidence of lifts/licks of the formalin-injected paw (Experiment 2B) were recorded in the manner described previously.

\section{Results and Discussion}

In Experiment 2A, there were no significant differences $(F=1.1)$ between paw-lick latencies on the initial exposure to the heated floor among the rats in Groups Hot/ Sal $(M=6.3, S E M=0.7)$ and $\mathrm{Hot} / \mathrm{Nal}(M=5.3$, 


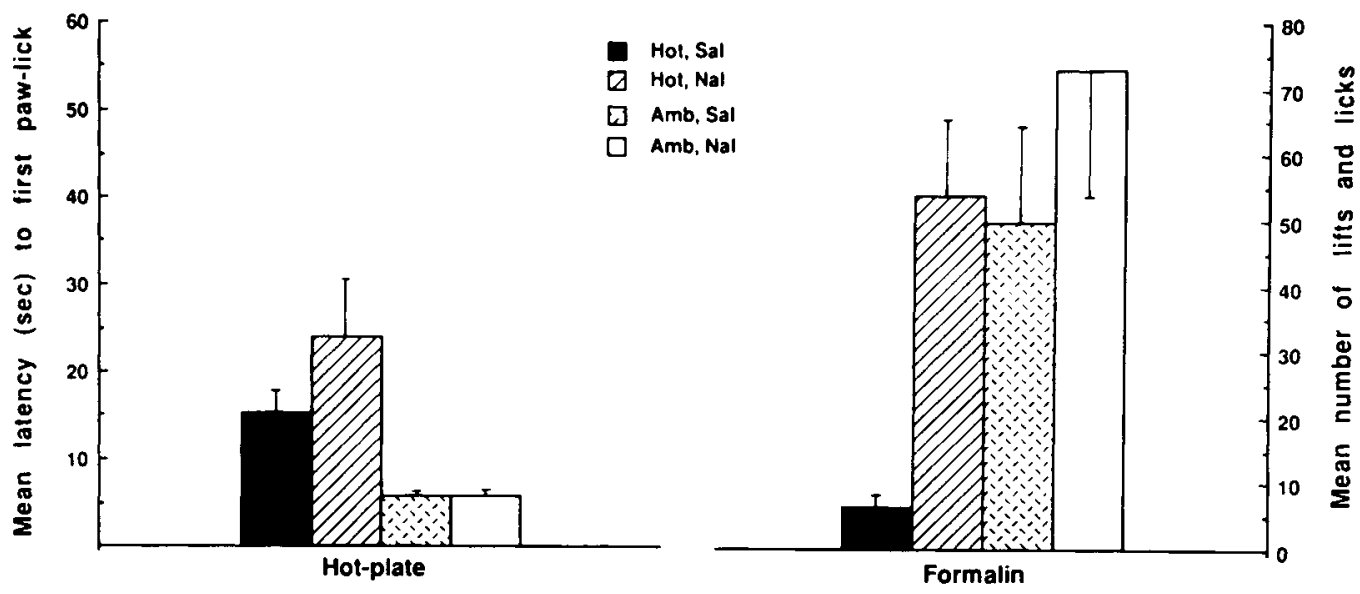

Figure 2. Mean ( $+1 S E M)$ latencies to paw lick in Experiment $2 A$ (left) and mean $( \pm 1 S E M)$ number of paw licks and paw lifts in Experiment 2B (right). Rats were preexposed to the heated (Hot) or nonheated (Amb) floor and tested with naloxone (Nal) or with saline (Sal).

$S E M=0.5$ ). The mean latencies with which the rats in each of the four groups licked their paws on the test exposure to the heated floor are shown in the left side of Figure 2. The rats in Groups Hot/Sal and Hot/Nal paw licked with significantly longer latencies than did those in Groups Amb/Sal and Amb/Nal $[F=15.5 ; F c(3,36)=$ 5.8], confirming that exposure to a heated floor results in conditioned hypoalgesic responses when rats are tested on that floor. There were no significant differences between paw-lick latencies among the rats in Groups $\mathrm{Hot} / \mathrm{Sal}$ and Hot/Nal $(F=3.1)$, showing that naloxone failed to attenuate the conditioned hypoalgesic responses resulting from preexposure to the heated floor. Finally, there were no significant differences between paw-lick latencies among the rats in Groups $\mathrm{Amb} / \mathrm{Sal}$ and $\mathrm{Amb} / \mathrm{Nal}(F<1.0)$, indicating that naloxone's failure to reverse the conditioned hypoalgesic responses was not due to a hypoalgesic effect of the drug.

In Experiment 2B, there were no significant differences $(F<1.0)$ between paw-lick latencies on the initial exposure to the heated floor among the rats in Groups Hot/ Sal $(M=7.5, S E M=0.7)$ and Hot/Nal $(M=7.0, S E M=$ 0.8 ). The mean number of responses to the formalininjected paw for the rats in each of the four groups when tested on the $23^{\circ} \mathrm{C}$ floor are shown in the right side of Figure 2. An inspection of these data suggests that naloxone increased pain responding, serving not only to attenuate the conditioned hypoalgesic responses among the rats preexposed to the heated floor, but also to antagonize opioid mechanisms among rats not previously subjected to pain in that apparatus. These observations were partially confirmed by the statistical analysis, which revealed evidence for conditioned hypoalgesic responses among rats preexposed to the heated floor and tested under saline, because there were significantly fewer pain responses among the rats in Group Hot/Sal than in the other three groups $(F=11.5)$. These conditioned hypoalgesic re- sponses were reversed by naloxone, because there were no significant differences between pain responses among the rats in Group Hot/Nal and those preexposed to a nonheated floor $(F<1.0)$. Although the rats in Group Amb/ Nal displayed more pain responses than did those in Group $\mathrm{Amb} / \mathrm{Sal}$, these differences did not reach a conventional level of significance $(F=1.5)$. Therefore, in contrast to previous findings (Harris \& Westbrook, in press; Sugimoto, Kuraishi, Satoh, \& Takagi, 1986), there was no statistical support in this experiment for activation of opioid mechanisms of pain control among rats tested with formalin in an apparatus not previously associated with pain.

\section{EXPERIMENTS 3A AND 3B}

The results of Experiments $2 \mathrm{~A}$ and $2 \mathrm{~B}$ demonstrated that the conditioned hypoalgesic responses induced by exposure to the heated floor were unaffected by naloxone when the rats were tested on the heated floor, but were reversed by this drug when they were tested on the nonheated floor after injection of formalin. In Experiments $3 \mathrm{~A}$ and $3 \mathrm{~B}$, we used cross-tolerance with morphine as a second assay of the nature of the antipain mechanisms mediating the hypoalgesic responses among rats tested in the presence of apparatus cues paired with exposure to the heated floor. Four groups of rats were repeatedly injected in the colony room with either saline or morphine, according to a drug schedule that has proved effective in inducing tolerance to the hypoalgesic effects of morphine when rats are tested for latencies to paw lick in response to a heated floor (Greeley \& Westbrook, 1990; Westbrook, Greeley, Nabke, \& Swinbourne, 1991; Westbrook, Greeley, Nabke, Swinbourne, \& Harvey, 1991). The rats were exposed under saline to either the heated or the nonheated floor of the hot-plate apparatus and then were tested for either latencies to paw lick in response to the heated floor 
(Experiment 3A) or incidence of licks/lifts of a formalininjected paw on the nonheated floor of the hot-plate apparatus (Experiment 3B).

\section{Method}

Subjects and Apparatus. In each experiment, there were 20 experimentally naive, male Wistar rats weighing between 340 and $500 \mathrm{~g}$. The apparatus was that used in the previous experiments.

Drugs. Morphine hydrochloride (Macfarlan Smith Ltd., Edinburgh) was dissolved in $0.9 \% \mathrm{w} / \mathrm{v}$ physiological saline. Both morphine and physiological saline were injected subcutaneously into the dorsal area of the neck at a volume of $1.0 \mathrm{ml} / \mathrm{kg}$.

Procedure. After handling, the rats were allocated to four weightmatched groups ( $n=5$ ) for each experiment. The rats in Groups Mor/Sal-hot and Mor/Sal-amb were injected with morphine, whereas those in Groups Sal/Sal-hot and Sal/Sal-amb received saline. These injections took place in the colony room. The dose of the drug was increased by $5 \mathrm{mg} / \mathrm{kg}$ every 3 days, so the rats had been injected on three occasions at each of four doses $(5,10,15$, and $20 \mathrm{mg} / \mathrm{kg}$ ) by the end of pretreatment. The injection regimen was discontinued for 4 days to allow the rats to recover from any acute withdrawal. On Day 17, they were injected with saline, placed into the wooden chambers for $30 \mathrm{~min}$, and exposed for $30 \mathrm{sec}$ to the hot-plate apparatus. Half of the morphine-experienced rats (Group Mor/Sal-hot) and half of the drug-naive rats (Group Sal/Salhot) were exposed to a $54^{\circ} \mathrm{C}$ floor, whereas the remainder (Groups $\mathrm{Mor} / \mathrm{Sal}$-amb and Sal/Sal-amb) were exposed to a $23^{\circ} \mathrm{C}$ floor. The temperature of the floor was changed from $52^{\circ} \mathrm{C}$ to $54^{\circ} \mathrm{C}$ in order to increase the level of the resulting hypoalgesic response (Westbrook, Greeley, Nabke, \& Swinbourne, 1991, Experiment 1). On Day 18, the rats were tested. In Experiment 3A, the rats were injected with saline, placed into the wooden chambers for $30 \mathrm{~min}$, and exposed for a maximum of $60 \mathrm{sec}$ to the $52^{\circ} \mathrm{C}$ floor of the hotplate apparatus. In Experiment $3 \mathrm{~B}$, the rats were injected with formalin in the manner described previously. After recovery from the anesthetic, each rat was injected with saline, placed into the wooden chambers for $30 \mathrm{~min}$, and exposed for $5 \mathrm{~min}$ to the $23^{\circ} \mathrm{C}$ floor of the hot-plate apparatus. Latencies to paw lick (Experiment $3 \mathrm{~A}$ ) and number of lifts/licks of the formalin-injected paw (Experiment 3B) were recorded in the manner described previously.

\section{Results and Discussion}

In Experiment 3A, there were no significant differences $(F<1.0)$ between paw-lick latencies among the rats in Groups Sal/Sal-hot $(M=4.0, S E M=0.8)$ and $\mathrm{Mor} / \mathrm{Sal}-$ hot $(M=3.5, S E M=0.5)$. The mean latencies with which the rats in each of the four groups paw licked on the test exposure to the heated floor are shown in the left side of Figure 3. The initial exposure to the heated floor resulted in hypoalgesic responses both in drug-naive and drug-experienced rats, because paw-lick latencies among the rats in Groups Sal/Sal-hot and Mor/Sal-hot were significantly longer $[F=23.0 ; F \mathrm{c}(3,16)=6.3]$ than those shown by the rats in Groups Sal/Sal-amb and Mor/Salamb. There were no significant differences between pawlick latencies of the rats in Groups Sal/Sal-hot and Mor/ Sal-hot $(F<1.0)$, confirming that the conditioned hypoalgesic responses induced by preexposure to the heated floor were not cross-tolerant with morphine. There were also no significant differences $(F<1.0)$ between paw-lick latencies among the rats tested in the presence of cues not previously associated with pain, indicating that a history of morphine did not increase pain sensitivity/ reactivity to the heated floor.

In Experiment 3B, there were no significant differences $(F<1.0)$ between paw-lick latencies among the rats in Groups Sal/Sal-hot $(M=3.7, S E M=0.4)$ and Mor/Salhot $(M=3.8, S E M=0.2)$ on the initial exposure to the heated floor. The mean number of responses to the formalin-injected paw when the rats in each of the four groups were tested on the $23^{\circ} \mathrm{C}$ floor of the hot-plate apparatus are shown in the right side of Figure 3 . An inspection of these data suggests that rats with a history of morphine display more pain responses than do drug-naive rats when tested in an aversively conditioned apparatus or in an apparatus not previously associated with pain.
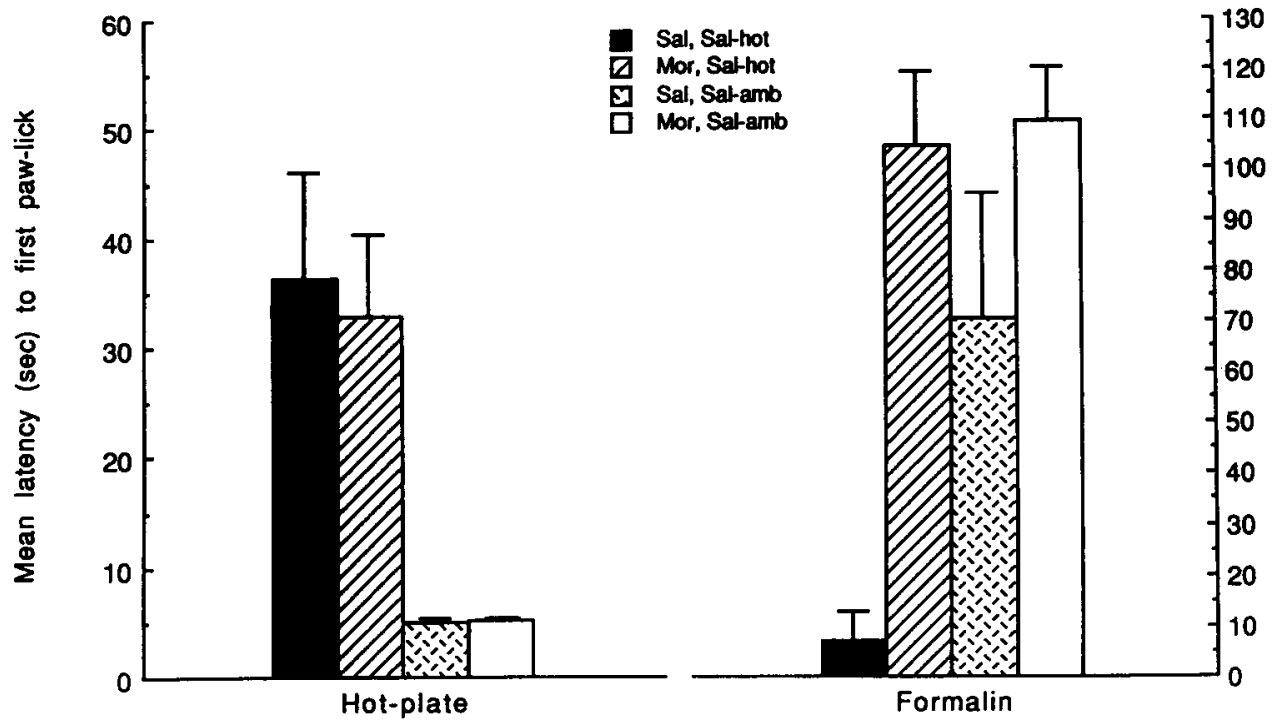

Figure 3. Mean (+1 SEM) latencies to paw lick in Experiment 3A (left) and mean $( \pm 1 S E M)$ number of paw licks and paw lifts in Experiment 3B (right). Rats with (Mor) or without (Sal) a history of morphine were injected with saline (Sal) and exposed to a heated (Hot) or nonheated (Amb) floor on the day before test. 
There was partial support for this suggestion. The rats in Group Sal/Sal-hot showed significantly fewer pain responses than did those in the three other groups $(F=23.3)$, confirming that preexposure to the heated floor resulted in conditioned hypoalgesic responses on the formalin test among the drug-naive rats. Although the rats in Group $\mathrm{Sal} / \mathrm{Sal}$-amb displayed fewer pain responses than did the drug-experienced rats (Groups Mor/Sal-hot and Mor/Sal$\mathrm{amb}$ ), these differences did not reach a conventional level of significance $(F=3.7)$. Although there was no statistical evidence for hyperalgesic responses among the drugexperienced rats, the conditioned hypoalgesic responses were completely prevented by the morphine pretreatment. This was evidenced by the failure to detect any significant differences between pain responding among the rats in Groups Mor/Sal-hot and Mor/Sal-amb $(F<1.0)$.

\section{GENERAL DISCUSSION}

The present experiments provide evidence that exposure to the heated floor of a hot-plate apparatus results in conditioned hypoalgesic responses when rats are tested in that apparatus. They also show that the form of these conditioned hypoalgesic responses is influenced by the nature of the test. Rats tested on the heated floor displayed conditioned hypoalgesic responses that were relatively insensitive to naloxone or to a history of morphine, whereas those tested with formalin on the nonheated floor recruited conditioned hypoalgesic responses that were reversed by naloxone and were cross-tolerant with morphine. These findings are consistent with the results from previous investigations of the nature of the antipain mechanisms engaged by aversively conditioned Pavlovian CSs. For example, naloxone-insensitive conditioned hypoalgesic responses have been reported in rats tested on a heated floor (e.g., Greeley \& Westbrook, 1990; Ross \& Randich, 1985), whereas naloxone-reversible responses to aversively conditioned CSs have been observed in rats tested with formalin pain (Fanselow \& Baackes, 1982; Fanselow \& Helmstetter, 1988; Williams et al., 1990).

The results from the present experiments, together with the findings reported by other laboratories, suggest that a number of variables modulate the nature of the conditioned hypoalgesic response. As mentioned earlier, one variable appears to be the amount learned about the association between the CSs and the noxious US and/or the aversiveness acquired by the CSs as a result of that association. For example, Lichtman and Fanselow (1991) used the tail-flick procedure to examine how variations in the number of environment-shock pairings would affect the form of conditioned hypoalgesic responses when rats were tested in that environment in the absence of shock. These investigators reported that rats given relatively few pairings displayed naloxone-sensitive responses, whereas those subjected to a greater number of environment-shock pairings showed naloxone-insensitive hypoalgesic responses. These results provide support for the suggestion that some inconsistencies in the literature with regard to the form of the conditioned hypoalgesic responses may have been due to differences in the levels of aversive conditioning among experiments. However, this suggestion cannot explain the present findings, which were obtained with rats tested in the presence of the same conditioned apparatus cues. Rather, the differences in the form of the conditioned hypoalgesic responses observed here are likely to be due to the pain test that was used. This conclusion is similar to that reached by Lichtman and Fanselow (1990), who exposed rats to a cat and measured tail-flick responses to radiant heat or electric shock. They found that the hypoalgesic responses provoked by the presence of the cat were reversed by naltrexone when the tail flick was elicited by heat, but not when the same response was induced by shock.

Although similar in topography, the paw-lifting and paw-licking responses to a heated floor and to a formalininjected paw may be controlled by pain signals acting upon different neural circuits, and hypoalgesia could be mediated by different neural mechanisms in these two tests (Abbott, Franklin, \& Libman, 1986; Abbott \& Melzack, 1982; Dennis \& Melzack, 1980; Ryan, Watkins, Mayer, \& Maier, 1985). Moreover, pain responses to a heated floor and to a formalin-injected paw are affected differently by the same pharmacological treatment. For example, daily administrations of morphine result in substantial tolerance in the hot-plate test (Westbrook, Greeley, Nabke, \& Swinbourne, 1991; Westbrook, Greeley, Nabke, Swinbourne, \& Harvey, 1991), but produce minor reductions in morphine's potency in the formalin test (Abbott, Franklin, Ludwick, \& Melzack, 1981). The central nervous system contains multiple mechanisms of pain control, and it is possible that distinct neurochemical systems act upon different forms of pain (Abbott, Melzack, \& Samuel, 1982; Lichtman \& Fanselow, 1990). Exposure to the conditioned apparatus cues in the present experiments may have activated both nonopioid and opioid mechanisms, with the former resulting in hypoalgesic responses to the pain produced by the heated floor and the latter mediating these responses to formalin pain. Alternatively, if nonopioid circuitry was engaged by the pain produced by the heated floor whereas opioid systems were (eventually) triggered by formalin pain (Sugimoto et al., 1986), then the conditioned apparatus cues may have served to potentiate activity in these circuits rather than acting directly on antipain mechanisms.

In summary, the present documentation of a critical role for the pain test in determining the form of conditioned hypoalgesic responses suggests that this factor may have contributed to the inconsistencies in the literature with respect to the activation of opioid versus nonopioid mechanisms of pain control by aversively conditioned CSs.

\section{REFERENCES}

Abbott, F. V., Franklin, K. B. J., \& Libman, R. B. (1986). A doseratio comparison of $\mathrm{mu}$ and kappa agonists in formalin and thermal pain. Life Sciences, 39, 2017-2024.

Abbott, F. V., Franklin, K. B. J., Ludwick, R. J., \& Melzack, R. 
(1981). Apparent lack of tolerance in the formalin test suggests different mechanisms for morphine analgesia in different types of pain. Pharmacology, Biochemistry \& Behavior, 15, 637-640.

Aввотt, F. V., \& MElzaCK, R. (1982). Brainstem lesions dissociate neural mechanisms of morphine analgesia in different kinds of pain. Brain Research, 251, 149-155.

Abbott, F. V., Melzack, R., \& Samuel, C. (1982). Morphine analgesia in the tail-flick and formalin pain tests is mediated by different neural systems. Experimental Neurology, 75, 644-651.

Chance, W. T., \& Rosecrans, J. A. (1979a). Lack of cross-tolerance between morphine and autoanalgesia. Pharmacology, Biochemistry \& Behavior, 11, 639-642.

Chance, W. T., \& Rosecrans, J. A. (1979b). Lack of effect of naloxone on autoanalgesia. Pharmacology, Biochemistry \& Behavior, 22, 643-646.

DenNis, S. G., \& MelzaCK, R. (1980). Pain modulation by adrenergic agents and morphine as measured by three pain tests. Life Sciences, 26, 1247-1259.

Dubuisson, D., \& Dennis, S. G. (1977). The formalin test: A quantitative study of the analgesic effects of morphine, meperidine, and brainstem stimulation in rats and cats. Pain, 4, 161-174.

FANSELOW, M. S. (1984). Shock-induced analgesia on the formalin test: Effects of shock severity, naloxone, hypophysectomy, and associative variables. Behavioral Neuroscience, 98, 79-95.

FAnselow, M. S. (1991). Analgesia as a response to aversive Pavlovian conditioned stimuli: Cognitive and emotional mediators. In M. R. Denny (Ed.), Fear, avoidance and phobias (pp. 61-86). Hillsdale, NJ: Erlbaum.

Fanselow, M. S., \& BaAckes, M. P. (1982). Conditioned fear-induced opiate analgesia on the formalin test: Evidence for two aversive motivational systems. Learning \& Motivation, 13, 200-221.

Fanselow, M. S., \& Helmstetter, F. J. (1988). Conditional analgesia, defensive freezing, and benzodiazepines. Behavioral Neuroscience, 102, 233-243.

Grau, J. W. (1987). The central representation of an aversive event maintains the opioid and non-opioid forms of analgesia. Behavioral Neuroscience, 101, 272-288.

Greeley, J. D., \& Westbrook, R. F. (1990). Some effects of exposure to a heat stressor upon the rat's subsequent reactions to that stressor. Quarterly Joumal of Experimental Psychology, 42B, 241-265.

HaRris, J. A., \& WeStBrooK, R. F. (in press). Effects of midazolam and naloxone in rats tested for sensitivity/reactivity to formalin pain in a familiar, novel or aversively conditioned environment. Psychopharmacology.

Lichtman, A. H., \& Fanselow, M. S. (1990). Cats produce analgesia in rats on the tail-flick test: Naltrexone sensitivity is determined by the nociceptive test stimulus. Brain Research, 533, 91-94.

Lichtman, A. H., \& Fanselow, M. S. (1991). Opioid and non-opioid conditional analgesia: The role of spinal opioid, noradrenergic, and serotonergic systems. Behavioral Neuroscience, 105, 687-698.

MAIER, S. F. (1989). Determinants of the nature of environmentally induced analgesia. Behavioral Neuroscience, 103, 131-143.

RODGER, R. S. (1967). Type I errors and their decision basis. British Journal of Mathematical \& Statistical Psychology, 20, 51-62.

Ross, R. T., \& RANDICH, A. (1985). Associative aspects of conditioned analgesia evoked by a discrete CS. Animal Learning \& Behavior, 13, 419-431.

Ryan, S. M., Watkins, L. R., Mayer, D. J., Maier, S. F. (1985). Spinal pain suppression mechanisms may differ for phasic and tonic pain. Brain Research, 334, 172-175.

Sugimoto, M., Kuraishi, Y., Satoh, M., \& TAKagi, H. (1986). Involvement of medullary opioid-peptidergic and spinal noradrenergic systems in the regulation of formalin-induced persistent pain. Neuropharmacology, 25, 481-485.

Watkins, L. R., Cobelli, D. A., \& MaYer, D. J. (1982). Classical conditioning of front paw and hind paw footshock induced analgesia (FSIA): Naloxone reversibility and descending pathways. Brain $R e$ search, 243, 119-132.

Westbrook, R. F., Greeley, J. D., Nabke, C. P., \& Swinbourne, A. L. (1991). Aversive conditioning in the rat: Effects of a benzodiazepine and of an opioid agonist and antagonist on conditioned hypoalgesia and fear. Journal of Experimental Psychology: Animal Behavior Processes, 17, 219-230.

Westbrook, R. F., Greeley, J. D., Nabke, C. P., Swinbourne, A. L., \& HARVEY, A. (1991). Effects of morphine and naloxone upon the reactions of rats to a heat stressor. Quarterly Journal of Experimental Psychology, 43B, 323-346.

Williams, J. L., Worland, P. D., \& SMITH, M. G. (1990). Defeatinduced hypoalgesia in the rat: Effects of conditioned odors, naltrexone, and extinction. Journal of Experimental Psychology: Animal Behavior Processes, 16, 345-357.

(Manuscript received November 24, 1992; revision accepted for publication November 22, 1993.) 